\title{
Soot volume fraction measurements over laminar pool flames of biofuels, diesel and blends
}

\author{
B. Tian ${ }^{\mathrm{a}}$, C. T. Chong ${ }^{\mathrm{b}}$, L. Fan ${ }^{\mathrm{a}}$, J.-H. Ng ${ }^{\mathrm{c}}$, C. Zhang ${ }^{\mathrm{a}}$, S. Hochgreb ${ }^{\mathrm{a}}$ \\ ${ }^{a}$ Department of Engineering, University of Cambridge, Trumpington Street, CB2 1PZ \\ Cambridge, UK \\ ${ }^{b}$ UTM Centre for Low Carbon Transport in cooperation with Imperial College London, \\ Universiti Teknologi Malaysia, 81310 Skudai, Johor, Malaysia \\ ${ }^{c}$ Faculty of Engineering and the Environment, University of Southampton Malaysia \\ Campus (USMC), 79200 Iskandar Puteri, Johor, Malaysia
}

\begin{abstract}
Biodiesel and blends with petroleum diesel have shown their potential as renewable alternative fuels for engines, with additional benefits of low particulate matter and low sulfate emissions. In this paper we measure the soot volume fraction produced by three different methyl esters processed biodiesels (extracted from palm (PME), soy (SME) and coconut (CME)), and their blends with petroleum diesel, in a series of co-flow stabilized laminar pool flames, using laser induced-incandescence (LII) and laser extinction optical methods. The soot volume fraction measurement results show that all neat biodiesels produce only up to $33 \%$ of the total soot volume compared to pure diesel, and that the total soot volume correlates directly with the degree of unsaturation of the biodiesels. Blending leads to approximately linear behaviour of total soot volume, with a shift in slope with smaller sensitivity towards neat diesel.
\end{abstract}

Email address: bt312@cam.ac.uk (B. Tian ) 
Keywords: Biodiesel, Soot, Laser induced incandescence, Laser extinction

\section{Introduction}

A variety of industrially processed bioderived fuels have been introduced as replacements for diesel fuel, such as palm, rapeseed, coconut and soy. These are processed and tailored as a replacement for diesel, with suitably low cetane numbers, and viscosities adjusted as additives for appropriate operation in existing engines. These replacement fuels typically have 10$15 \%$ oxygen as elemental composition, which offers an additional benefit in the form of lower soot emissions, with some variations on the effect on $\mathrm{NO}_{\mathrm{x}}$ [1]. A typical biodiesel consists of a mixture of monoalkyl esters of long-chain methyl esters produced via the transesterication process, in which the triglycerides contained in vegetable oils and animal fats react with methanol to form methyl esters and glycerol [2]. The chemical oxidation and soot formation pathways of biodiesel have been investigated in a number of studies [3, 4]. Although many studies have been produced in engines, fewer measurements have been made in well controlled devices suitable for model comparisons, such as vaporised laminar co-flow diffusion flames [5, 6], counterflow diffusion flames [7], spray flames [8], high pressure injection constant volume combustion chambers $[9,10]$ and wick-fed lamp diffusion flames [11]. Nerva et al. [10] studied the soot formation of soy biodiesel using soot extinction, laser induced incandescence (LII) and luminosity at pressures up to $6.7 \mathrm{MPa}$ and $1000 \mathrm{~K}$. The soot concentration for biodiesel was found to be lower by an order of magnitude compared to diesel, highlighting the role of oxygen and molecular structure of biodiesel in reducing sooting propensity. In a similar 
but separate study [9], soy biodiesel was found to yield a higher value of soot mass fractions compared to butanol. Unlike diesel, butanol is a relatively short alcohol chain dthat shows low sooting propensity. The effect of oxygen concentration in the vessel was also investigated. The flame luminosity and soot production were shown to decrease with decreasing oxidizer content in the mixture, whereas higher ambient temperatures in the chamber increased soot production. The propensity of sooting for model biodiesels has been studied by Feng et al. [7] in a non-premixed counter-flow flame configuration using biodiesel surrogates, in the form of fatty acid esters. The model biodiesel fuels were shown to produce signicantly lower soot levels compared to the corresponding n-alkanes with similar carbon number. Interestingly, unsaturated methyl ester (methyl-crotonate: $\mathrm{C}_{5} \mathrm{H}_{8} \mathrm{O}_{2}$ ) was shown to exhibit higher sooting propensity compared to the corresponding saturated methyl ester (methyl-butanoate: $\mathrm{C}_{5} \mathrm{H}_{10} \mathrm{O}_{2}$ ), indicating that the effect of the unsaturation level in biodiesel on soot formation could be prominent. This is in agreement with results from an engine test operated using linseed biodiesel: this fuel with a higher unsaturation level emitted higher particulate matter and hydrocarbons compared to the less unsaturated palm biodiesel [12].

Kholgy et al. [5] measured the soot volume fraction of a biodiesel surrogate consisting of $50 \%$ n-decane/50\% methyl-octanoate (as a surrogate for methyl oleate) in an co-flow diffusion flame, using the laser extinction method. The results were used as validation target for chemical kinetic models. Their computational study showed that the soot volume fraction and temperature profiles for the biodiesel surrogate are similar to that of ndecane, indicating a negligible effect of ester moiety on soot formation. The 
result shows the low degree of unsaturation in biodiesel, rather than oxygen composition, may play the main role in lowing soot formation. MerchanMerchan et al. [6] used a similar setup and measurement technique to investigate the extent of soot formation in the case of soy and canola biodiesels. Both biodiesels exhibited similar flame temperatures and soot volume fraction profiles. Tran et al. [11] investigated the sooting behaviour of soybean biodiesel/diesel blends using LII over a wick-fed lamp, showing that the biodiesel produced significantly lower soot, and that the variation was proportional to the blended fraction. Finally, Tran et al. [13] considered the burning and emission characteristics of biodiesels over a pool fire, but no soot measurements were made.

The present study addresses the following needs: (a) to provide absolute measurements of soot volume fraction over a controlled laminar pool fire of a known fuel; (b) to contrast the formation of soot over a pool fire for a range of biofuels with different degrees of unsaturation and for a range of blending conditions with diesel fuel.

Extinction-calibrated LII has been proven to be a robust non-intrusive method for soot volume fraction $\left(f_{v}\right)$ measurement in flames [14-16]. However, in high soot loading environments, LII suffers from significant signal trapping [17]. To tackle the problem, a deconvolution method was used in the present study to correct the 2D LII images and provide quantitative measurements for future studies. 

the flickering of the flame. The biodiesels tested in this work are methyl

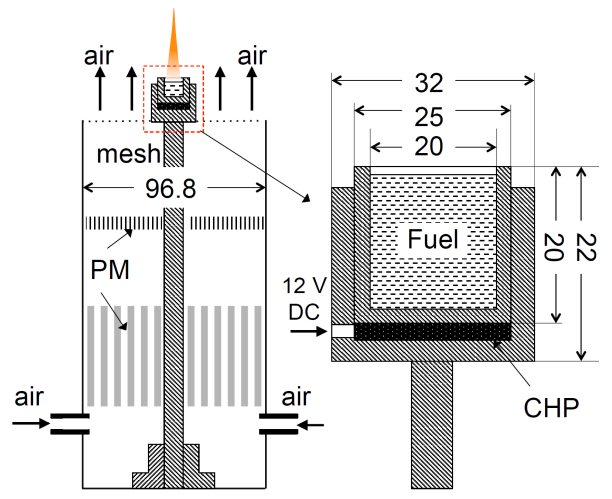
present study. The burner consists of a co-flow tube $(D=96.8 \mathrm{~mm})$, a stainless steel fuel cup $(D=20 \mathrm{~mm}$, depth $=20 \mathrm{~mm}$, wall thickness $=2.5$ $\mathrm{mm}$ ) and a holder for the cup. The dimensions of the cup and holder are shown in Fig. 1. A ceramic heating plate $\left(\mathrm{CHP}, \mathrm{D}=24 \mathrm{~mm}, 12 \mathrm{~V}, \leq 240^{\circ} \mathrm{C}\right)$ is used underneath the pool to keep a constant temperature of the fuel around $120{ }^{\circ} \mathrm{C}$. A co-flow air of $18.2 \mathrm{~cm} / \mathrm{s}$ is added around the fuel pool to reduce

Figure 1: Co-flow stabilised laminar pool fire burner. CHP: ceramic heating plate; PM: porous material. Units in $\mathrm{mm}$. Dimensions in $\mathrm{mm}$, not to scale.

79

\section{Methodology}

\subsection{Experiment}

Figure 1 shows the co-flow stabilized laminar pool burner used in the

esters (ME) produced via a transesterification process from the feedstock of palm, soy and coconut oils, and are denoted as PME, SME and CME respectively. The composition of the biodiesels is measured using a standard Gas Chromatograph using a gas chromatograph (GC, Agilent 7620A) based on EN14103 standard, and listed in Table 2. The measured average formula of PME, SME and CME are: $\mathrm{C}_{18.1} \mathrm{H}_{34.9} \mathrm{O}_{2.0}, \mathrm{C}_{18.8} \mathrm{H}_{34.5} \mathrm{O}_{2.0}$ and $\mathrm{C}_{13.5} \mathrm{H}_{26.9} \mathrm{O}_{2.0}$, 


\begin{tabular}{lrrr}
\hline & PME & SME & CME \\
\hline C8:0 & 0 & 0 & 6.78 \\
C10:0 & 0 & 0 & 5.61 \\
C12:0 & 0 & 0 & 51.00 \\
C14:0 & 0.93 & 0 & 18.51 \\
C16:0 & 39.85 & 11.62 & 9.26 \\
C18:0 & 3.55 & 4.51 & 1.66 \\
C18:1 & 43.14 & 23.03 & 6.06 \\
C18:2 & 12.53 & 54.22 & 1.12 \\
C18:3 & 0 & 6.62 & 0 \\
\hline Unsaturation & 0.62 & 1.51 & 0.08 \\
Avg. C chain & 17.1 & 17.8 & 12.5 \\
MW (g/mol) & 284.3 & 291.5 & 221.2 \\
$\Delta H$ (MJ/kg) & 37.3 & 37.0 & 35.2 \\
H & 12.29 & 11.84 & 12.18 \\
C & 76.46 & 77.18 & 73.36 \\
O & 11.25 & 10.98 & 14.46 \\
\hline
\end{tabular}

Table 1: Top section: Composition (mass percentage) of biodiesels measured using GCMS. C8:0 means the main chain of eight carbon atoms with zero $\mathrm{C}=\mathrm{C}$ double bonds. Bottom section: Properties and elemental mass percentage of biodiesels. The degree of unsaturation is calculated by multiplying the mass fraction of each species times the associated number of $\mathrm{C}=\mathrm{C}$ double bonds. Heat values $\Delta H$ are from Ref. [18].

respectively. All biofuels tested contain $\geqslant 10 \%$ (mass fraction) of oxygen, and have a relatively low overall degree of unsaturation $(\leqslant 1.51)$, and are thus are naturally expected to yield lower soot emissions. The behaviour of soot over

pool flames was investigated for a series of biodiesels and their blends with petroleum diesel (D100). The blends are indicated by the initial of the biofuel ( $\mathrm{P}, \mathrm{S}$ or $\mathrm{C}$ ) and the percent by mass used in the mixture, e.g. P20 refers to $20 \%$ by mass in palm oil biodiesel. In all tests, the co-flow air flow velocity is kept at $18.2 \mathrm{~cm} / \mathrm{s}$. The fuel consumption rate of each case is measured by weighing the fuel burned over 10 min stable combustion, resulting in values 
between 0.085-0.097 g/min.

The 2D LII measurements were performed using an similar set-up to that in Ref. [16]. The laser source is a $532 \mathrm{~nm} \mathrm{Nd:YAG} \mathrm{laser} \mathrm{(Litron} \mathrm{nanoPIV)}$ firing at $10-25 \mathrm{~Hz}$. The laser beam is collimated into a parallel sheet by a series of beam shaping optics, followed by an aperture to generate a verified top-hat profile. The LII signal induced by the laser sheet was captured by an ICCD camera (LaVision Nanostar $1024 \times 1280$ pixels), fitted with a lens (Nikon AF Micro Nikkor 60 mm, f/5.6) and a band filter (Thorlabs FB400-40, central $\lambda=400 \pm 8 \mathrm{~nm}, \mathrm{FWHM}=40 \mathrm{~nm}$ ) which minimises the luminosity from PAH fluorescence, $\mathrm{C}_{2}$ and flame radiation. A delay of $20 \mathrm{~ns}$ was applied to the intensifier gate to avoid the interference of PAH LIF and residual laser scatter. A relatively short intensifier gate width of $30 \mathrm{~ns}$ was used to avoid bias towards larger particles [19]. The laser fluence used in the LII measurement was carefully selected. Figure 2 shows the dependence of the LII signal on the fluence of the laser sheet for the highest soot producing cases D100, P100, S100 and C100. The LII signal at each fluence represents the average value of 200 images at $20 \mathrm{~Hz}$ after background subtraction, obtained from the signal intensity between 0 to $35 \mathrm{~mm}$ height above the burner (HAB). The fuel pool surface is kept $1 \mathrm{~mm}$ below the cup lip before each measurement, and during the 10 second measurement, no significant decrease of the fuel surface level is observed as the fuel consumption rate is small $(<0.1$ $\mathrm{g} / \mathrm{min})$. All values are normalized using the maximum value of the case for purposes of locating the signal peak. In all cases, the LII signal rises rapidly with increasing laser fluence, as the temperature of the particles increase, reaching the sublimation point and an approximately fixed temperature and 


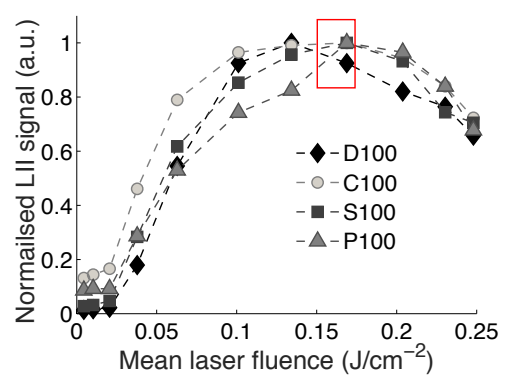

Figure 2: Fluence dependence of the LII signal for four unblended cases as a function of the fluence of laser sheet; the peak or plateau region (in the marked rectangle) is selected for the LII measurements. The values of LII signal intensities of each case are normalised using by maximum value for each fuel.

fuel cases. Figure 3 shows the beam profile and variance averaged over 200

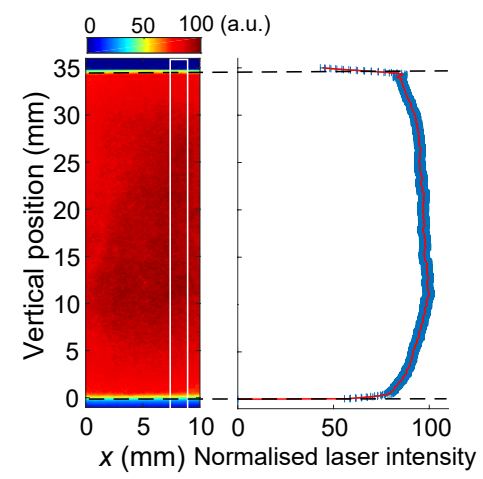

Figure 3: Normalised laser beam intensity profile used for LII excitation. Left: Rhodamine 6G fluorescence excited by laser sheet in a cuvette; right: integrated fluorescent light intensity profile over the region (red line) over the rectangle marked with a white border. Blue error bars indicate the signal variance shot-to-shot.

signal at a fluence around $0.15 \mathrm{~J} / \mathrm{cm}^{2}$, as indicated in the marked rectangle. In this region, the LII signal is less sensitive to local laser fluence, which allows a simplified description of the signal. In this work, we assume that the fluence dependence of LII signal of all blended cases is similar to the pure fuel cases, as their response curve should be somewhere in between the pure fuel cases. Figure 3 shows the beam profile and variance averaged over 200

shots at $20 \mathrm{~Hz}$, as characterised by the resulting fluorescence in a cuvette 
containing Rhodamine $6 \mathrm{G}$ dye. The local intensity fluctuation of the laser sheet as represented by the standard deviation is lower than $5 \%$, and the corresponding error introduced by fluctuations in spatial fluence is smaller than 3\%. All images are averaged after background noise subtraction. The nominal spatial resolution is $50 \mu \mathrm{m} /$ pixel for an imaging area of $35 \times 35 \mathrm{~mm}^{2}$.

\subsection{LII calibration and correction}

Laser extinction measurements are performed for a quantitative calibration of the LII signal [14]. A diode laser (Omicron LuxX-638-150, $638 \mathrm{~nm}$ wavelength) is used as laser source for extinction. The laser beam intensity ahead and behind soot absorption, $I_{0}$ and $I_{t}$, respectively, are determined using photodiodes (Thorlabs SM05PD1A Silicon Photodiode, 350-1100 nm). The extinction ratio of the laser beam $A=I_{t} / I_{0}$ can be expressed as $[14,16]$ :

$$
A=\frac{I_{t}}{I_{0}}=\exp \left(-\int K_{e} \mathrm{~d} x\right)
$$

where $x$ is the path length across the sampling region, and $K_{e}$ is the extinction coefficient. The extinction coefficient $K_{e}$ can be related to the local soot volume fraction $f_{v}$ in the Rayleigh regime (particle smaller than wavelength) as:

$$
K_{e}=\frac{6 \pi E(m)}{\lambda_{e}} f_{v}
$$

where $E(m)$ is the absorption function of soot $E(m)=-\operatorname{Im}\left(\frac{m_{e}^{2}-1}{m_{e}^{2}+2}\right)$ and $m_{e}$ is the complex refractive index of soot at the extinction wavelength $\lambda_{e}$ (638 $\mathrm{nm})$.

The local value of $f_{v}$ can be determined in the axisymmetric system by spatial differentiation of the total absorption factor $A$, which is a function 
of chord distance $x$, obtained at the centreline of the flame via inverse Abel transform $[14,16]$ :

$$
f_{v}(r)=\frac{\lambda_{e}}{6 \pi^{2} E(m)} \int_{x}^{\infty} \frac{[\ln A(x)]^{\prime}}{\sqrt{x^{2}-r^{2}}} \mathrm{~d} r
$$

where $r$ is the radial distance. In the present study, the location $\mathrm{HAB}=25$ $\mathrm{mm}$ in D100 flame is selected to conduct extinction measurements, as this is close to the location of maximum integrated LII signal $\int S_{m} d x$. The $f_{v}$ value is then calibrated from the measured LII signal intensity $S_{m}$ by assuming that the LII and extinction signals are linearly proportional (as detailed in the following sections).

No reduction of LII signal is observed along the propagation direction of the laser sheet, indicating the whole probe volume is in the plateau region of LII measurement (Fig. 2), and a correction for the attenuation of the laser sheet is considered unnecessary. However, because the flames in the present study produce relatively high soot concentrations, the LII signal collected is subject to trapping as it travels from the excitation plane to the camera, and a correction on the signal trapping is necessary before the calibration [17]. Since the flame is axisymmetric, the attenuation of the LII signal in the flame due to signal trapping (as a function of $x$ ) can be estimated from the absorption ratio obtained for the extinction measurement along chord distance $x$. In the present study, we measured $A$ at $\mathrm{HAB}=25 \mathrm{~mm}$ for $\mathrm{D} 100$ along $x$ over a step distance of $0.25 \mathrm{~mm}$ from $x=-5 \mathrm{~mm}$ to $5 \mathrm{~mm}$, generating a well-resolved $A(x)$. By combining Eqs. (1) and (2) and considering that the LII absorption only occurs through one half of the symmetric flame, the 
corrected LII signal $S(x)$ can be obtained from the measured signal $S_{m}(x)$ :

$$
S(x)=S_{m}(x) A(x) \exp \left(-\frac{\lambda_{e} E\left(m_{L}\right)}{2 \lambda_{s} E\left(m_{e}\right)}\right)=S_{m} K_{c}(x)
$$

where $K_{c}(x)$ is the correction constant; $m_{L}$ and $m_{e}$ are calculated at 400 $\mathrm{nm}$ and $638 \mathrm{~nm}$, respectively, to account for the different absorption ratios at the two wavelengths. Values of $E(m)$ at the two wavelengths are taken as 0.41 and 0.27 , respectively, referred to the latest review in [20] using a RDG-FA model corrected for internal multiple scattering effects. The LII signal at $\mathrm{HAB}=25 \mathrm{~mm}$ in D100 flame can finally be calibrated using the extinction data by considering that the integrated $f_{v}$ across the centerline chord at a certain HAB yields a total logarithmic attenuation. We assume that the corrected LII signal $S$ is proportional to the soot volume fraction with a linear coefficient, such that $S=C f_{v}[14,16,21]$, so that at the flame centerline, we have:

$$
\ln \frac{I_{t}}{I_{0}}=\frac{6 \pi E\left(m_{e}\right)}{\lambda_{e}} \frac{1}{C} \int_{-\infty}^{+\infty} S(r) \mathrm{d} r
$$

The calibration constant $C$ is therefore determined using Eq. (5), whose value is $2.9156 \times 10^{8}$ at $\mathrm{HAB}=25 \mathrm{~mm}$ in $\mathrm{D} 100$ flame. This value of $C$ is assumed to remain the same for all flames, since the soot produced by different liquid fuels shares similar optical properties [22] and the imaging parameters are kept unchanged throughout the experiment. A correction and calibration method for all other cases is then possible, using the known value of $C$, with $f_{v}$ as the only unknown variable, and one value of $A$ for the chord centerline 
at the same reference point. Considering the at a fixed chord position $x$ at in flame center, $r=x, S_{m}(x)=S_{m}(r)$, we have:

$$
C f_{v}(r)=S_{m}(r) \exp \left(-\frac{12 \pi E\left(m_{L}\right)}{\lambda_{s}} \int_{0}^{\infty} \frac{r f_{v}(r)}{\sqrt{r^{2}-x^{2}}} \mathrm{~d} r\right)
$$

The exponential factor represents the attenuation of the LII signal expressed in Eq. (4). By discretizing a cross section at a particular height of the flame into a series of concentric rings, and numbering the values from $i=0$ to $N$, the Eq. (6) can be written as:

$$
C f_{v}(i)=S_{m}(i) \exp \left(-\frac{6 \pi E\left(m_{L}\right)}{\lambda_{s}} \sum_{j=i}^{N} f_{v}(j) \Delta_{i, j}\right)
$$

where $\Delta_{i, j}$ is given by Eq. (8) by assuming the distance between two adjacent rings (pixels) is $\delta$ :

$$
\Delta_{i, j}=\left\{\begin{array}{c}
\delta\left(\sqrt{j^{2}-i^{2}}-\sqrt{(j-1)^{2}-i^{2}}\right), i<j \leqslant N \\
0, j \leqslant i
\end{array}\right.
$$

For $i=N$, the signal is emitted from the outermost ring, which is considered as unattenuated: $S(N)=S_{m}(N)$, so we have $f_{v}(N)=S_{m}(N) / C$. For other rings from $i=N-1$ to $i=1$, as the term $f_{v}(i)$ is the only unknown variable in Eq. (7) and appears in both sides of the equation, and can therefore be solved for iteratively in descending order from $i=N-1$ to $i=1$. 


(at

\section{Results and discussion}

Both corrected and uncorrected $f_{v}$ profiles at $\mathrm{HAB}=25 \mathrm{~mm}$ for the D100 flame are shown in Fig. 4 and compared with the extinction data. The value of the correction constant $K_{c}$ is obtained by extinction measurements in 0.25 $\mathrm{mm}$ steps along the radius (described in Section 2.2) and interpolated to a resolution of $50 \mu \mathrm{m}$ to correct $S_{m}$. The data shows that signal trapping causes about $14 \%$ underestimation of $f_{v}$ at the flame center, and less than $5 \%$ at the edges. Figure 5 shows the natural luminosity of all tested flames and

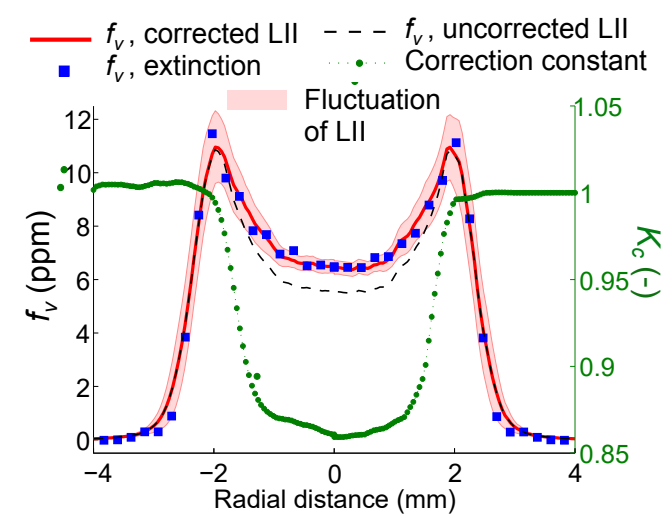

Figure 4: Corrected (red line with pink shaded fluctuation region) and uncorrected (dashed line) $f_{v}$ profile at $\mathrm{HAB}=25 \mathrm{~mm}$ of $\mathrm{D} 100$ flame, compared to values obtained from extinction $f_{v}$ (blue squares), and correction coefficient $K_{c}$ (green dots). $K_{c}$ is obtained by moving the extinction measurement in $0.25 \mathrm{~mm}$ steps and interpolated to the resolution of $50 \mu \mathrm{m}$.

the corresponding $f_{v}$ map from $\mathrm{HAB}=0$ to $35 \mathrm{~mm}$. The fuel consumption rate for each case is noted on each flame photo. The fuel consumption rate is within $7 \%$ for all 16 cases, but the visible flame heights are widely different, from $25 \mathrm{~mm}$ to more than $80 \mathrm{~mm}$ (sooting flames). All pure biodiesel visible flame heights are similar, and shortest in height, increasing approximately linearly towards the highest visible heights of the pure diesel. In the latter 

material (Fig. S1) for ease of use by models. The spatial profiles of $f_{v}$ at

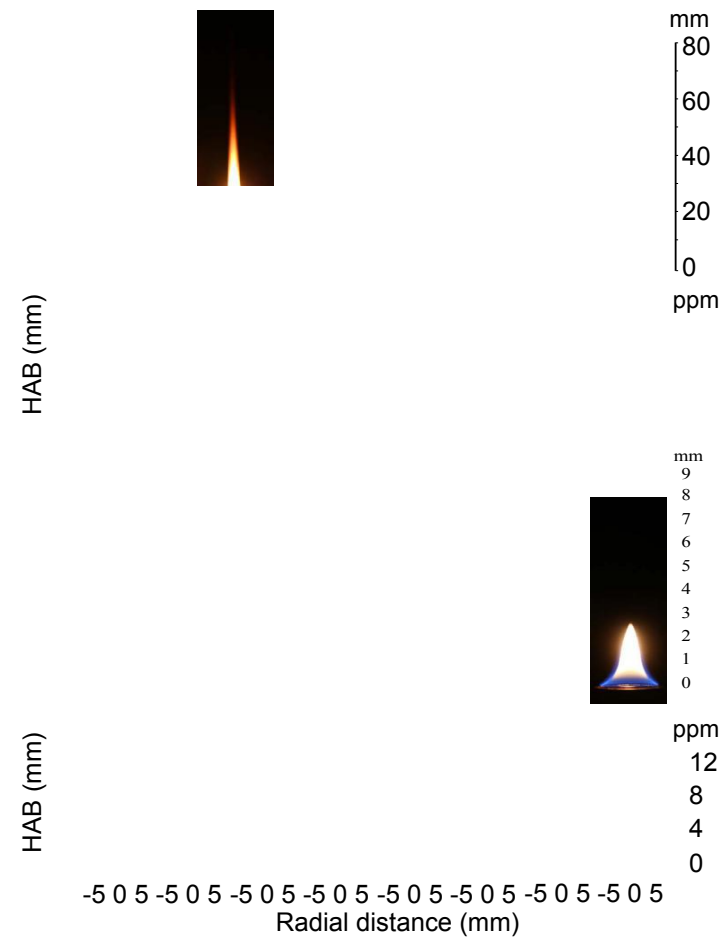

Figure 5: Natural luminosity of tested flames and corresponding $f_{v}$ map from $\mathrm{HAB}=0$ to $35 \mathrm{~mm}$. The fuel consumption rate of each case is noted on each subfigure in units of $10^{-2}$ $\mathrm{g} / \mathrm{min}$. 
is plotted using red dashed lines in each sub-figure as a reference. At a particular height, the values of $f_{v}$ replicate a similar linear behavior as the maximum $f_{v}$ against the blend ratio of biofuels. The profiles indicate that for cases with biodiesel ratios lower than $60 \%$, at this particular height, the maximum $f_{v}$ appears in the annular region, in contrast with cases with high biodiesel ratio ( $80 \%$ and $100 \%$ ), where the maximum $f_{v}$ appears along the flame centerline.

The appearance of soot depends on the residence time of the fuel within a fuel-rich region at high temperatures. The heating value of the three fuels are similar, and all about 15\% percent lower than petroleum diesel [18]. The expected adiabatic temperatures for the different fuels are within $35 \mathrm{~K}$ based on the heating values and equilibrium calculations. In the case of D100, soot is promptly formed at high temperatures near the base of the flame after a short residence time, and continues as the heat is transferred towards the centerline of the flame. More soot results near the high temperatures at the edge than from the cooler centerline. In the case of the oxygenated biodiesels, the high temperatures at the base are insufficient to produce sufficient soot fractions over a short residence time. Only after sufficient residence time at high temperatures, away from oxidiser does the biodiesel pyrolysis create sufficient soot at the centerline. At higher HABs, after sufficient residence time at high temperatures all soot profiles converge to maxima at the centerline, as shown in Fig. 5. The maximum soot volume fraction for each case is shown in 7 , as a function of biodiesel mass fraction. CME and all of its blends with petroleum diesel produces the least $f_{v}$, while SME produces the most, certainly beyond the $40 \%$ blending ratio. This observation is consis- 


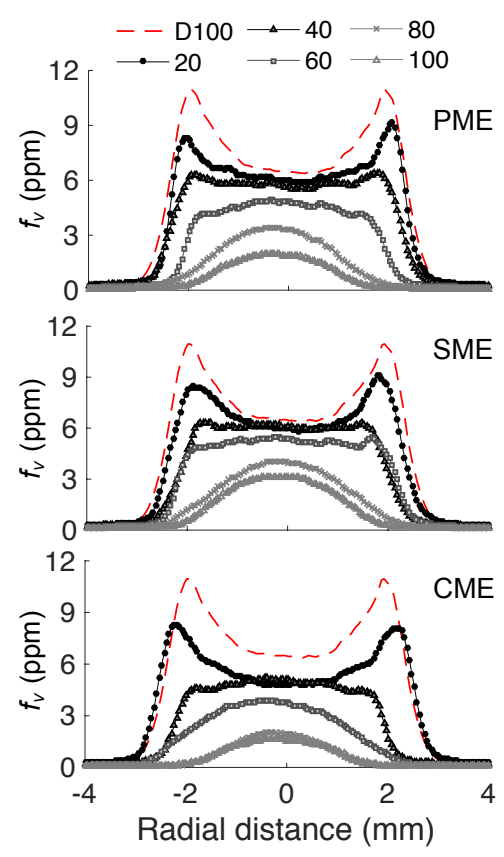

Figure 6: Profile of $f_{v}$ at $\mathrm{HAB}=25 \mathrm{~mm}$ for three series of flames. D100 is plotted using red dashed lines in each sub-figure as reference. 

values showing S20 is slightly higher, and one where P20 is higher. A final

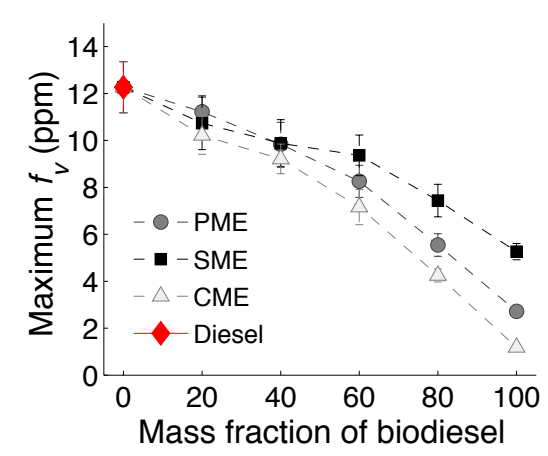

Figure 7: Maximum $f_{v}$ as a function of biodiesel mass fraction.

265 266 among the three tested fuels, compared with SME, whose saturated composition mass ratio is only about $16 \%$. Over a blend ratio from 0 to $80 \%$, the maximum $f_{v}$ is reduced by a factor of about 2.9 for CME, 2.2 for PME and 1.7 for SME, showing the addition of biodiesel can significantly suppress the formation of soot. A parallel comparison among three biodiesels shows the degree of unsaturation is a key factor for soot formation in tested flames. The highly saturated CME (degree of unsaturation 0.08 ) produces only $22.4 \%$ of maximum $f_{v}$ compared with SME (degree of unsaturation 1.51) in pure form, and in almost all blended cases. CME blend produces the least soot, while SME produces the most. One exception to this trend happens when the mass blend ratio is $20 \%$, and the maximum $f_{v}$ in P20 is slightly higher than that of S20. This is yet not explained in the current research. The measurements were repeated 3 times; the results are all very close to each other, with 2

comparison can be made by considering the soot flux in the axial direction,

tent with the fact that CME has the most saturated bonds in biodiesel (93\%) 


(1)
biofuel, not shown) have a non-zero soot flux at the top of the image.

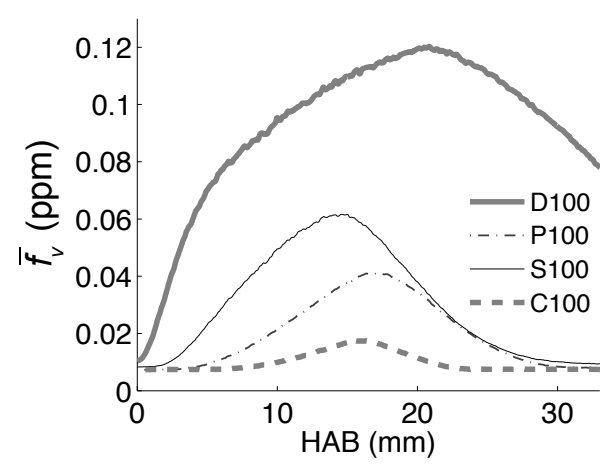

Figure 8: Normalised mean soot volume fraction $\frac{1}{\pi R^{2}} \int_{0}^{R} 2 \pi r f_{v}(r) \mathrm{d} r$ in D100, P100, S100 and $\mathrm{C} 100$ flames, where $R$ is the radius of the pool.

277 the fuel mass consumption rates are within 10\%. Therefore it is reasonable to assume that the value of $u$ is not significantly different. In that case, the total relative mean soot flux going into the flame region is represented by a total area weighted soot volume fraction $\bar{f}_{v}$, as a function of height above the burner, (Fig. 8). As expected, the mean soot volume fraction ranks in a similar way as the maximum $f_{v}$ plots. However, the mean value goes to zero for the biofuels across the flame, the D100 (and the blends above $40 \%$

Extinction calibrated laser induced incandescence (LII) is applied to measure the soot volume fraction in laminar pool fires fueled with three different

which should scale as

$$
\dot{V}_{s}=2 \pi \int r f_{v} u \mathrm{~d} r
$$

where $u$ is the mean axial velocity through the profile. The heating value of all biofuels is similar, and about 10-15\% lower than that of D100 [18], and 
biodiesels (PME, SME and CME) and their blends with petroleum diesel. The biodiesels have similar elemental composition but different degrees of unsaturation. The measured levels of maximum and total volume integrated over the image show that peak soot volume fractions produced by neat biofuels in this situation are 10.6 to $32.6 \%$ that of diesels, and that the fuel soot production ranks in order of degree of unsaturation. Blending leads to lower soot values, although the value is not linear across the entire range, with a slower reduction in total soot amount for blending of small quantities of biodiesel, followed by a faster decrease towards neat biofuel.

\section{Acknowledgements}

B. Tian is funded through a fellowship provided by ZEPI. C. Zhang is funded through a fellowship provided by CSC. The authors gratefully acknowledge the financial support from Universiti Teknologi Malaysia under grant number RG84263, and a Newton Advanced Fellowship (NA160115) for C. T. Chong.

\section{References}

[1] M. Lapuerta, O. Armas, J. Rodriguez-Fernandez, Progress in Energy and Combustion Science 34 (2008) 198 - 223.

[2] J. V. Gerpen, Fuel Processing Technology 86 (2005) 1097 - 1107. Biodiesel Processing and Production.

[3] O. Herbinet, W. J. Pitz, C. K. Westbrook, Combustion and Flame 154 (2008) $507-528$. 
[4] J. P. Szybist, J. Song, M. Alam, A. L. Boehman, Fuel Processing Technology 88 (2007) 679 - 691. Biofuels for Transportation.

[5] M. R. Kholghy, J. Weingarten, M. J. Thomson, Proceedings of the Combustion Institute 35 (2015) 905-912.

[6] W. Merchan-Merchan, S. McCollam, J. F. C. Pugliese, Fuel 156 (2015) $129-141$.

[7] Q. Feng, A. Jalali, A. M. Fincham, Y. L. Wang, T. T. Tsotsis, F. N. Egolfopoulos, Combustion and Flame 159 (2012) 1876-1893.

[8] C. Allouis, M. Romano, F. Beretta, L. Viegas, a. D'Alessio, Combustion Science and Technology 134 (1998) 457-475.

[9] H. Liu, C. F. F. Lee, M. Huo, M. Yao, Energy and Fuels 25 (2011) 3192-3203.

[10] J.-G. Nerva, C. L. Genzale, S. Kook, J. M. García-Oliver, L. M. Pickett, International Journal of Engine Research 14 (2013) 373-390.

[11] M. K. Tran, D. Dunn-Rankin, T. K. Pham, Combustion and Flame 159 (2012) 2181-2191.

[12] M. Salamanca, F. Mondragon, J. R. Agudelo, P. Benjumea, A. Santamaria, Combustion and Flame 159 (2012) 1100-1108.

[13] V. Tran, C. Morton, R. N. Parthasarathy, S. R. Gollahalli, International Journal of Green Energy 11 (2014) 595-610. 
323

324

[14] C. R. Shaddix, K. C. Smyth, Combustion and Flame 107 (1996) 418452.

[15] H. A. Michelsen, C. Schulz, G. J. Smallwood, S. Will, Progress in Energy and Combustion Science 51 (2015) 2-48.

[16] B. Tian, Y. Gao, S. Balusamy, S. Hochgreb, Applied Physics B 120 (2015) 469-487.

[17] F. Liu, K. a. Thomson, G. J. Smallwood, Applied Physics B 96 (2009) 671-682.

[18] S. K. Hoekman, A. Broch, C. Robbins, E. Ceniceros, M. Natarajan, Renewable and Sustainable Energy Reviews 16 (2012) 143 - 169.

[19] E. Cenker, G. Bruneaux, T. Dreier, C. Schulz, Applied Physics B 118 (2015) 169-183.

[20] A. Bescond, J. Yon, F. X. Ouf, C. Rozé, A. Coppalle, P. Parent, D. Ferry, C. Laffon, Journal of Aerosol Science 101 (2016) 118-132.

[21] F. Liu, G. J. Smallwood, Applied Physics B 112 (2013) 307-319.

[22] S. S. Krishnan, K.-C. Lin, G. M. Faeth, Journal of Heat Transfer 123 (2001) 331. 
340 List of supplementary files

341 Figure S1. Soot volume fraction $f_{V}$ distribution (data-readable TIFF 342 figure) in all tested cases. 


\section{List of figure captions}

Figure 1. Co-flow stabilised laminar pool fire burner. CHP: ceramic heating plate; PM: porous material. Units in $\mathrm{mm}$. Dimensions in $\mathrm{mm}$, not to scale.

Figure 2. Fluence dependence of the LII signal for four unblended cases as a function of the fluence of laser sheet; the peak or plateau region (in the marked rectangle) is selected for the LII measurements. The values of LII signal intensities of each case are normalised using by maximum value for each fuel.

Figure 3. Normalised laser beam intensity profile used for LII excitation. Left: Rhodamine 6G fluorescence excited by laser sheet in a cuvette; right: integrated fluorescent light intensity profile over the region (red line) over the rectangle marked with a white border. Blue error bars indicate the signal variance shot-to-shot.

Figure 4. Corrected (red line with pink shaded fluctuation region) and uncorrected (dashed line) $f_{v}$ profile at $\mathrm{HAB}=25 \mathrm{~mm}$ of D100 flame, compared to values obtained from extinction $f_{v}$ (blue squares), and correction coefficient $K_{c}$ (green dots). $K_{c}$ is obtained by moving the extinction measurement in $0.25 \mathrm{~mm}$ steps and interpolated to the resolution of $50 \mu \mathrm{m}$.

Figure 5. Natural luminosity of tested flames and corresponding $f_{v}$ map from $\mathrm{HAB}=0$ to $35 \mathrm{~mm}$. The fuel consumption rate of each case is noted on each subfigure in units of $10^{-2} \mathrm{~g} / \mathrm{min}$.

Figure 6. Profile of $f_{v}$ at $\mathrm{HAB}=25 \mathrm{~mm}$ for three series of flames. D100 is plotted using red dashed lines in each sub-figure as reference.

Figure 7. Maximum $f_{v}$ as a function of biodiesel mass fraction.

Figure 8. Normalised mean soot volume fraction $\frac{1}{\pi R^{2}} \int_{0}^{R} 2 \pi r f_{v}(r) \mathrm{d} r$ in 
368 D100, P100, S100 and C100 flames, where $R$ is the radius of the pool. 


\section{Tables}

\begin{tabular}{lrrr}
\hline & PME & SME & CME \\
\hline C8:0 & 0 & 0 & 6.78 \\
C10:0 & 0 & 0 & 5.61 \\
C12:0 & 0 & 0 & 51.00 \\
C14:0 & 0.93 & 0 & 18.51 \\
C16:0 & 39.85 & 11.62 & 9.26 \\
C18:0 & 3.55 & 4.51 & 1.66 \\
C18:1 & 43.14 & 23.03 & 6.06 \\
C18:2 & 12.53 & 54.22 & 1.12 \\
C18:3 & 0 & 6.62 & 0 \\
\hline Unsaturation & 0.62 & 1.51 & 0.08 \\
Avg. C chain & 17.1 & 17.8 & 12.5 \\
MW (g/mol) & 284.3 & 291.5 & 221.2 \\
$\Delta H$ (MJ/kg) & 37.3 & 37.0 & 35.2 \\
H & 12.29 & 11.84 & 12.18 \\
C & 76.46 & 77.18 & 73.36 \\
O & 11.25 & 10.98 & 14.46 \\
\hline
\end{tabular}

Table 2: Top section: Composition (mass percentage) of biodiesels measured using GCMS. C8:0 means the main chain of eight carbon atoms with zero $\mathrm{C}=\mathrm{C}$ double bonds. Bottom section: Properties and elemental mass percentage of biodiesels. The degree of unsaturation is calculated by multiplying the mass fraction of each species times the associated number of $\mathrm{C}=\mathrm{C}$ double bonds. Heat values $\Delta H$ are from Ref. [18]. 